\title{
Language-specificity in monolingual and bilingual later lexical development
}

Anne White

Faculty of Psychology and Educational Sciences, KU Leuven, Belgium

\author{
Barbara C. Malt
}

Department of Psychology, Lehigh University, USA

Steven Verheyen

Faculty of Psychology and Educational Sciences, KU Leuven, Belgium

Gert Storms

Faculty of Psychology and Educational Sciences, KU Leuven, Belgium

Author Note

\section{Corresponding author:}

Anne White

Faculty of Psychology and Educational Sciences

KU Leuven - University of Leuven

Tiensestraat 102 - box 3711

3000 Leuven

Belgium

Email: anne.white@kuleuven.be

Phone: +3216324827 


\begin{abstract}
Although children may productively use concrete nouns after limited exposure, complete mastery of adult-like patterns of noun usage can take up to 14 years. We evaluated whether a transition from universal to language-specific naming is part of the refinement in later lexical development, and we compared how this refinement plays out in monolingual versus bilingual children. We collected free naming data for pictures of nearly 200 household containers from 499 Belgian children, aged 5 to 14, and adults, raised with either (a) only French, (b) only Dutch, or (c) both French and Dutch. Both monolingual and bilingual 5-year olds produced largely shared naming patterns, and for both groups, naming patterns became more language-specific and also more consistent within-language over time. However, monolinguals and bilinguals diverged in some aspects of their developmental profiles. Monolinguals started to introduce language-specificities to their naming pattern beginning at age 8 , but differentiation between languages did not emerge for bilinguals until age 12. Consensus on name choice increased across ages for both groups, but bilinguals showed more consensus at all ages, reflecting smaller vocabularies and less differentiation. Thus monolingual and bilingual children follow a similar trajectory from shared to language-specific patterns of word use, but bilinguals differentiate later and for only some words. This study demonstrates that a transition from shared to language-specific naming is a key aspect of later lexical development, but the developmental course differs in detail between monolingual and bilingual children.
\end{abstract}

Keywords: lexical differentiation, artifact categories, bilingualism, bilingual lexicon 


\section{Language-specificity in monolingual and bilingual later lexical development}

One of the earliest tasks of language acquisition is to map meanings to word forms. Starting in the first year, young children engage in this process using a variety of strategies and sources of information (E. V. Clark, 1995; Golinkoff \& Hirsh-Pasek, 2008; Markman, 1990). In doing so, they achieve a functional use of their early words (Carey, 1978). However, the initial mapping is not necessarily the same as the full adult word knowledge. Children take up to 14 years to narrow in on the adult meanings and usage patterns for many common words. They show under- and over-extensions in word production well past the early years of word learning (Ameel, Malt, \& Storms, 2008, 2014; Saji et al., 2011; Tillman \& Barner, 2015; Verheyen, Ameel, \& Storms, 2011), ), and they also show discrepancies from adult usage in a receptive task (that is, when being offered name choices) (Ameel et al., 2014).

One reason for this long learning trajectory is that in many conceptual domains children do not start out with the full set of words that adults use. New words entering their vocabulary may trigger a process of adjustment to the meanings associated with others that are already present (Ameel et al., 2008; E. V. Clark, 1973; Saji et al., 2011). The adjustment is not instantaneous on acquiring a new vocabulary item, though. It may take some time to figure out what elements of meaning are associated with each word (Ameel et al., 2008; Saji et al., 2011). Children also have an evolving understanding of the world itself, which can feed into their evolving word knowledge (Ameel et al., 2008).

Still, it might seem surprising that children take such a long time to make the necessary adjustments to converge to an adult naming pattern, especially for relatively familiar and frequently talked about domains. The lengthy learning trajectory may be due to the language-specific nature of word meanings. Languages vary in the number and kind of distinctions that they lexicalize in many -possibly most- conceptual domains. Domains where such differences have been attested include color and taste, spatial relations, body parts, locomotion, and household objects (see Malt \& Majid, 2013, for review). This means that children are not simply figuring out a perceptually 
or conceptually obvious universal set of meanings; they are figuring out language-specific configurations of meaning elements and non-obvious patterns of usage relevant for the language(s) they happen to be learning. The overarching goal of the current study is to advance understanding of the nature of later lexical development by probing how this is accomplished in monolingual and bilingual children.

\section{Learning language: from universal to language-specific}

The question of how children end up mastering differently structured languages starting from an equivalent basis is central to understanding language acquisition more generally. In many areas of language development, children appear to bring to the learning task shared biases and abilities that create a developmental path from universal tendencies in performance toward greater language-specificity. For instance, for phonology, it is well established that young infants can distinguish the phonemes of all languages (Kuhl, 2000). As they gain exposure to the language of their environment, their discriminative capacity is re-shaped until they discriminate only those relevant to that language (e.g., Kuhl, 2000; Pallier, Christophe, \& Mehler, 1997). Similarly, in morphosyntax, children start out with shared strategies (e.g., for encoding motion in sentences) and do not acquire the preferred strategy of their language (e.g., encoding path vs. manner of motion) until age three to five (e.g., Hohenstein, 2005; Maguire et al., 2010).

With regard to the lexicon, a variety of proposals have suggested that children have some early, presumably widely shared concepts (whether innate or acquired through experience) that precede and help with word learning (e.g., R. Brown, 1973 ; E. V. Clark, 2001; H. H. Clark, 1973 Hespos \& Spelke, 2004 Slobin, 1985). However, there must be some language specificity in the environmental input from the earliest moments, given that languages differ in even naming of common objects and actions. Indeed, some studies have highlighted children's early acquisition of language-specific aspects of labeling patterns. For instance, Korean children appreciate the relevance of the tightness of fit dimension in labeling spatial relations by 24-30 months (Bowerman 
\& Choi, 2001, 2003), and Tzeltal-speaking children recognize that their language distinguishes among acts of eating according to characteristics of what is eaten (crunchy vs. soft, etc.) within the first two years (P. Brown, 1998). Since the language input children receive from their adult caregivers is always language-specific, the possibility of early language-specific output in children is plausible. One might expect that if there is a transition from universal to language-specific in word learning, it would be accomplished by the end of early childhood. Indeed, past studies of extended lexical evolution examining monolingual development have often implicitly assumed language-specificity throughout monolingual lexical development. Figure 1, for instance, illustrates the lexical learning trajectory of monolinguals as theorized by Storms, Ameel, and Malt (2015). Monolinguals learning different languages were assumed to have distinct starting points and to develop in parallel.

Still, the language-specificity of word meanings and the empirical observation of the lengthy trajectory toward adult-like mastery suggest that working out details of what is captured by the lexical items of the native language(s) might be a substantial part of later lexical development. Although they appreciate the relevance of tight versus loose fit in their language by two or two and a half, Korean children use their word for tight fit in places where adults would not (Bowerman \& Choi, 2001). Early sensitivity to some language-specific dimensions of meaning is not the same as a full grasp of the language-specific adult-like meaning and use of a word.

Such a shift might be explained by the similarity of language learning to semi-supervised learning (Vandist, Schryver, \& Rosseel, 2009). While constructing their vocabulary, children do not receive naming information for every object they encounter, only some objects are explicitly named by their caregivers. In this semi-supervised learning environment (e.g., Vandist et al., 2009), it is likely that children use perceptual similarity between objects to infer the extension of their early vocabulary words. Since perceived similarity shows only negligible differences between speakers of different languages (Malt, Sloman, Gennari, Shi, \& Wang, 1999)), a similarity-based naming pattern will show universal characteristics. As children receive more language-specific 
feedback, they can gradually acquire more language-specific information and move away from this universal, similarity-based naming pattern.

\section{Current study}

A more complete understanding of the nature of lexical evolution requires comparing development in more than one language. Only by directly comparing learners of different languages can we identify to what extent there are shared aspects of early word use and on what timeline, as well as how development of language-specificity unfolds. Past studies focus on the trajectory of monolingual versus bilingual lexical development (Storms et al., 2015; White, Malt, \& Storms, 2017). In these studies monolingual French and Dutch-speaking children serve as a reference group to examine the bilingual developmental trajectory. Monolingual reference groups are not directly compared to one another. In the current work, we compare all learner groups explicitly to evaluate a potential shift from shared to language-specific characteristics of lexical development. Neither is it known at what point in development such a transition may occur - whether children are using their vocabulary within a domain in language-specific ways in early childhood, or whether the shift toward language specificity occurs only in later lexical development.

The current study examines the word learning trajectory of children aged 5 to 14 for names for common household objects. Previously, Ameel et al. (2008) provided the first large-scale demonstration of a long learning trajectory for such words, asking children to freely name objects. In a follow-up study, Ameel et al. (2014) showed that discrepancies from adult usage persist up to age 11 in a receptive task (that is, when being offered name choices), not only in the original production task that entails retrieving words from memory. Other studies have also documented an extended period of refinement of meaning (e.g., Saji et al., 2011; Tillman \& Barner, 2015, Verheyen et al., 2011).

A first specific goal is to identify whether children past early childhood (age 5) are already showing language-specific patterns of word use, or whether they still use shared, 
presumably more similarity-based, patterns of naming regardless of language. If the latter, then the question becomes when they begin to show language specificity in their word use.

We also ask whether the developmental trajectory differs for monolinguals compared to bilinguals. It is known that bilingual adults' use of words in their two languages is less distinct than the use of the same words by monolinguals of the two languages (e.g., Ameel, Malt, Storms, \& Van Assche, 2009; Ameel, Storms, Malt, \& Sloman, 2005; White, Malt, \& Storms, 2017; Zinszer, Malt, Ameel, \& Li, 2014). That is, adult bilinguals treat roughly equivalent words in the two languages as more fully equivalent than they are to monolingual speakers, a phenomenon labeled bilingual convergence. ('Convergence' here refers to a status at a moment in time, not a process of change over time.) Convergence implies less language specificity, raising the question of how bilingual lexical development differs from monolingual.

Storms et al. (2015) compared word use patterns for bilingual and monolingual children and found that bilingual children of age 5 and older showed more convergence than same-aged monolingual children did for the same two languages. Storms et al. also found that correspondence between bilinguals' naming patterns increased with age while they decreased for monolinguals. Their analysis thus suggested a trajectory of increasing convergence across ages in bilinguals, implicating an early language-specificity with more mutual influence between the languages as acquisition proceeds, as illustrated in Figure 1, panel A.

However, White, Malt, Verheyen, and Storms (2017) noted that the analysis by Storms et al. did not adjust correctly for differences in naming consistency across ages. When appropriate adjustments for differences in consistency were made, results suggested that, if anything, bilinguals tended toward diverging more with age, suggesting that they are also acquiring more language-specificities over the course of later lexical development. White et al. thus suggested a decreasing convergence across ages, whereby bilingual children start with a universal naming pattern and gradually learn the language-specificities of their two languages as illustrated in Figure 1, panel B. 
Given the conflicting results regarding the developmental trajectory of bilingual children, a second specific goal of the current study is to clarify the bilingual lexical developmental process by (a) replicating and extending the previous results to establish whether increasing or decreasing convergence occurs across ages; and (b) comparing the bilingual to the monolingual trajectory, probing whether and how bilinguals move from universality to language-specificity in light of the adult convergence between their patterns of word use. The data also permit us to probe details of the trajectories including vocabulary size and its relation to the development of language specificity, and name consensus levels at different ages. We can ask whether later lexical development entails in part a shift in naming consensus, and whether reaching some critical mass of vocabulary triggers the development of language specificity.

To address these issues, we collected free naming data for a large set of common household objects from Belgian monolingual and bilingual children, aged 5 through 14 . Monolinguals spoke either French or Dutch, and bilinguals spoke both, allowing us to compare word use in the same two languages (with the same dialects of each) for the monolinguals and bilinguals, and to compare both to data from adults of the same populations. We compared naming patterns both quantitatively (Analysis 1) and through projection of word extensions onto object similarity spaces created from similarity data (Analysis 2) to better understand the nature of changes over the course of development.

\section{Method}

\section{Participants}

We collected naming data from functional monolingual and bilingual children of five different age groups: 5, 8, 10-, 12-, and 14-year olds. The monolingual Dutch- and French-speaking children were recruited from elementary and high schools in Dutchand French-speaking communities in Belgium. Bilingual children were recruited via advertisements in local newspapers. Adult data were taken from White, Malt, and Storms (2017). Table 1 shows the number of participants per age, language group 
(Dutch- versus French-speaking) and speaker group (monolingual versus bilingual). Functionally monolingual participants, hereafter referred to as monolinguals, typically had some knowledge of the other language through formal instruction at school but did not use this language in daily activities. Bilinguals were raised with both languages via a Dutch-speaking mother and French-speaking father or vice versa.

Language background information was collected using questionnaire asking about age, gender, place where the participant was raised, native language of each parent, language spoken with the mother, language spoken with the father, how consistently the same language is spoken with the same parent, what language was spoken in every stage of the school career and during leisure activities, which language is used the most, in which language the participant thinks spontaneously, interaction in other languages, and an estimate of proficiency in both languages. For the younger children the questionnaire was filled in by one of the parents. Most families indicated that both parents consistently speak their own native language to the child from birth onwards.

Table 2 shows the average self- or parent-reported language proficiency for French and Dutch for every bilingual age group. Most participants in this study indicated greater proficiency in Dutch than French. The self-rated proficiency corresponds to the findings concerning vocabulary size. In bilingual participants we observe a smaller vocabulary size in French as compared to Dutch (for details see Appendix A). From this we conclude that most of our bilingual participants are dominant in Dutch.

\section{Materials}

Stimuli were 192 pictures of storage containers taken from White, Malt, and Storms (2017). The stimulus set contained objects that can be found at work or at home and were likely to receive the names bottle, jar, container, or box in English. In Dutch, the most frequently given names are fles, pot, doos, and bus. In French, the most frequently given names are bouteille, flacon, pot, and boîte. Examples can be found in Figure 2, 


\section{Procedure}

Naming data. The adult naming data were described in White, Malt, and Storms (2017). They were collected using an online survey (Qualtrics, Provo, UT, USA) in which participants were asked to name each pictured object individually.

Monolinguals performed the naming task once, bilinguals twice, that is, once in each language. Instructions were based on Malt et al. (1999) and were identical to those used by Ameel et al. (2005) and Storms et al. (2015). Participants were instructed to give the objects in the photographs whatever name seemed best or most natural, and to name the object itself and not the content. Objects were named one by one, and the order of stimuli was randomized for each participant. For bilinguals, the order of languages was counterbalanced. Instructions were always given in the language in which the task was performed. Children were tested at home or at school in a quiet environment. Naming data for the children were collected individually in an oral naming task for the youngest age groups and all bilingual children. Children performed the task at their own pace and were allowed to take breaks if necessary. Older monolingual children were tested in groups, viewing the pictures in a slide show and writing the name on an answer sheet.

Sorting data. Sorting data were used to construct a common underlying representation reflecting similarity between the objects (Rosenberg \& Kim, 1975). Sorting data were taken from White, Malt, and Storms (2017), who collected them from Belgian Dutch-speaking adults. These data provide a measure of the similarity between each pair of objects. Since perceived similarity collected from different language groups shows negligible differences, no data were collected for French-speaking adults (Ameel et al., 2005 Malt et al., 1999). In the procedure used by White et al., participants were instructed (following Malt et al., 1999) to look through the pictures and then sort the objects into piles based on overall qualities of each object, focusing on any feature (or combination of features) of the object that seemed important or natural. Participants were asked not to sort two objects into the same pile because of what they contain (such as ketchup and mayonnaise), unless the objects themselves were alike in an overall way. Participants could use as many piles as they wanted, with the restriction that they 
should use at least two piles. Unlike previous studies, participants were told that they could group piles together into clusters. Since this task is to complex for children, only adult sorting data were collected.

All data described in this study are available on the Open Science Framework $(\mathrm{OSF})$

\section{Results}

\section{Tabulation of naming data}

We tallied the frequency of each name produced for each object. Following Malt et al. (1999), tallies were based on the head noun of the response (i.e., adjectives were not taken into account). Diminutive forms of names were combined with the non-diminutive forms into a single category. As expected, vocabulary increased with age for all groups (see Appendix A). There was no difference in vocabulary size (measured by the number of different names produced across individuals) between monolinguals and bilinguals for Dutch in any of the age groups. For French, bilingual children at each age show a smaller vocabulary compared to monolinguals. However, this difference is no longer present for adults (see Appendix A).The difference between Dutch and French reflects dominance in Dutch for many of the bilingual participants (see Table 2).

\section{Tabulation of sorting data}

As reported in White, Malt, and Storms (2017), for every participant an individual similarity matrix was constructed based on the sorting of the stimuli. For each possible pair of stimuli, a pair placed together in a pile received a score of 1 and a pair placed in separate piles received 0 . In the case of clustered piles, pairs within the same pile received a 1 score. Stimulus pairs within the same cluster, but not sharing the same pile, received 0.5. The reliability of the average similarity data reached 0.92 , estimated using the split-half technique $\mathrm{g}^{1}$ followed by the Spearman-Brown formula.

\footnotetext{
${ }^{1}$ The reliability estimate reported here is based on the average of 10,000 random splits of the data.
} 


\section{Analysis 1: Trajectory of differentiation between languages}

The first analysis we present clarifies the trajectory of differentiation between languages for monolingual and bilingual children by testing whether there are significant differences in naming patterns between Dutch and French at each age. The youngest age groups would display a naming pattern that is not significantly different between Dutch and French if their naming pattern is still shared. It is, however, possible that children display a naming pattern significantly different for both languages in the youngest age groups. We will compare the extent of the language effect between age groups and between monolinguals and bilinguals to identify universality versus language-specificity in later lexical development.

Following Malt et al. (1999) and Ameel et al. (2005), object x object matrices were constructed for each individual participant. For each possible pair of objects named by an individual participant, the pair was assigned a value of 1 if both objects received the same name from that participant and a value of 0 if they were named differently. These matrices are thus language-neutral, indicating whether two objects received the same name, regardless of language. We then calculated all pairwise correlations between the matrices for individuals of the same age group and speaker group (monolingual or bilinguals), including both within-language matrices (monolinguals of the same language, and bilinguals in one of their languages) and between-language matrices (monolinguals of different languages, and bilinguals in their two different languages). Intra-individual correlations in Dutch and French of bilingual participants were excluded from the analysis. The resulting correlation values were transformed to normalize the sampling distribution, using a Fisher Z-transformation. The Z-transformed correlations were analyzed with a two (speaker group: bilinguals versus monolinguals) by two (same language versus different language) by six (age group) factorial ANOVA. By working with individual participants' object x object matrices rather than object $\mathrm{x}$ name matrices aggregated across each group as in Storms et al. (2015), differences in consistency are directly represented in the data (see below) and separated from changes in convergence. 
The language effect (i.e., the comparison of correlations when the language is the same versus different) is illustrated in Figure 3 for every age group. The overall rising height of the lines reflects increased within-group consistency in naming across ages. Interestingly, consistency remains below the adult level even at age 14, suggesting that narrowing in on the preferred adult labeling conventions continues even after 14 . The key results, however, lie in the value for same-language compared to different-language at each age. The lower set of bars shows that for monolinguals, at age 5 the correlations are slightly lower when calculated across languages than when calculated within the same language. From here, the difference increases steadily across ages, indicating that the naming patterns of the two languages are becoming increasingly distinct. The upper set of bars shows that for bilinguals, the correlations remain as high between as within languages through age 10. It is not until 12 that they begin to separate. Furthermore, the separation is never as pronounced as it is for monolinguals. We also observe that the average correlation between two bilinguals is consistently higher than the correlation between two monolinguals.

The trends evident in Figure 3 are supported by statistical analysis. There was a main effect of age, $F(5,17913)=7.70, p<.001$; language (same versus different), $F(1,17913)=364.25, p<.001 ;$ and speaker group (monolingual versus bilingual) $F(1,17913)=2628.46, \mathrm{p}<.001$. Most importantly, there was a significant three-way interaction between speaker group, language, and age, $F(5,17913)=6.645, p<.001$, with the language effect growing stronger as a function of age, but more so for monolinguals than for bilinguals. On average, the correlation between individuals speaking the same language was higher than between individuals speaking a different language, and the correlation between bilinguals was on average higher than between monolinguals.

For monolinguals there is a significant language effect at all ages, except for the five-year-olds $(t(17913)=2.67, p<.05)$. Post-hoc contrasts showed the presence of a language effect for 8-year olds $(t(17913)=4.75, p<.001)$; for 10-year olds $(t(17913)=9.72, p<.001)$; for 12-year olds $(t(17913)=15.03, p<.001) ;$ for 14 -year 
olds $(t(17913)=12.22, p<.001)$ and for adults $(t(17913)=16.21, p<.001)$. For bilinguals the language effect was absent in ages 5 to 10. For the 12- and 14-year-olds there was a marginally significant language effect $(t(17913)=2.38, p<.1$ and $t(17913)=2.26, p<.1$ respectively), that reached significance only in the adult group $(t(17913)=7.37, p<.001)$.

The difference between the language effect for monolinguals and bilinguals was not significant $(t(17913)=1.10)$ at age 5 and marginally significant at age 8 $(t(17913)=2.59, p=.02)$. From age 10 onwards this difference in effect is significant with $t(17913)=3.92, p<.001$ for the 10 -year olds, $t(17913)=7.32, p<.001$ for the 12 -year-olds, $t(17913)=6.44, p<.001$ for the 14 -year olds and $t(17913)=16.54$, $p<.001$ for the adults.

Pairwise post-hoc contrasts between different age groups reveal that, on average, the correlation between two different individuals increases with age. The only exception was the contrast between 5 - and 8-year olds $(t(17913)=-2.760, p<.01)$, that shows that the correlation between two different 8-year-olds was on average a little lower than between two different 5-year-olds. All other pairwise post-hoc contrasts between age groups show a rising trend in the correlation between two different individuals within an age group: 8 - versus 10-year olds $(t(17913)=18.675, p<.001) ; 10$ - versus 12-year-olds $(t(17913)=3.30, p<.01) ; 12$ - versus 14-year-olds $(t(17913)=8.58, p<.001) ;$ 14 -year-olds versus adults $(t(17913)=20.934, p<.001)$.

In short, the adult comparison replicates past findings of bilingual convergence (Ameel et al., 2005, White, Malt, Verheyen, \& Storms, 2017). The child data show that monolingual children are beginning to pick up aspects of naming patterns specific to their language by age 8 . However, this differentiation is modest until later childhood, with monolinguals still acquiring details of their native naming pattern that distinguish it from those of other languages throughout later childhood. Furthermore, bilingual children are delayed in incorporating language-specificities into their naming relative to monolinguals, treating the naming patterns as substantially the same up to age 10 . They do differentiate their languages more over time (contrary to Storms et al., but 
consistent with the revised analysis of White et al., 2017). When they do so, however, it is only to a minor extent even through age 14 .

\section{Analysis 2: Visualization of trajectory of differentiation between}

languages. To provide a more intuitive and nuanced understanding of changes in word use patterns across ages and groups, we visualized naming proportions in each participant group (that is, the proportion of participants who produced a given name to a stimulus) as an overlay on the similarity space for several of the major terms in each language. By using naming proportions instead of a discrete cutoff point (as Ameel et al., 2014, did for monolingual receptive judgments) to identify when a group uses a name for an object, we can better see the initiation and change of use of the words. Naming proportions were visualized for the category names with the highest frequency in adult uses: fles, pot, doos and bus in Dutch, and bouteille, pot, boîte and flacon in French (White, Malt, \& Storms, 2017).

A two-dimensional representation of the adult sorting data was constructed using non-metric multidimensional scaling (MDS; Borg \& Groenen, 2005, Kruskal \& Wish, 1991). Naming proportions for each group were then plotted as an overlay. The darkness of the grey reflects the proportion of individuals in a group who produced that name for a given object. Figure 4 presents the naming patterns for fles and bouteille (similar to the English bottle). Differences in the extensions of these words for monolingual adults can be seen in the bottom outer panels. Adult Dutch speaking monolinguals use fles for more stimuli than adult French speaking monolinguals do for its rough equivalent, bouteille.

Consistent with Ameel et al. (2008), there is overextension (at a group level) of fles and bouteille compared to adult usage, for both monolingual and bilingual children. The overextension gradually decreases with age as children narrow in on the adult naming pattern. What this figure makes clear is the striking similarity between naming patterns of the youngest age groups regardless of the language and speaker group. That is, even as relatively late as age 5, naming patterns are largely shared.

Figure 4 also illustrates how the naming patterns in Dutch and French become 
more distinct with increasing age, but more so for monolinguals than bilinguals. In adulthood, the differences between the Dutch and French naming pattern are greater for monolinguals than bilinguals. There is a clear difference in the extension of fles and bouteille in monolingual adults, but this difference is barely noticeable in adult bilinguals. The disappearance of disagreement among participants is also evident in the gradual reduction of lighter gray regions across ages. Similar observations can be made for the labels pot $_{\text {Dutch }}$ and pot $_{\text {French }}$ (similar to jar in English), and Dutch doos and French boite (similar to box in English). Graphs for these words are provided in Appendix C1 and Appendix C2 respectively.

Figures 5 and 6 visualize the evolution of bus in Dutch and flacon in French. Storms et al. (2015) found that bilinguals' total vocabulary lagged behind that of monolinguals at each age up until age 14 (see also Appendix A). As one would expect, the gap was due to some terms, such as bus and flacon, that are applicable to fewer objects in the domain, being used less. We see this pattern again in the current Figures 5 and 6 . Both bus and flacon are present in the vocabulary of the monolingual children much earlier than they are for bilingual children. For monolinguals, when the nouns first appear, there is initial underextension (age 8 for bus, and age 10 for flacon) as compared to the adult pattern, followed by temporary overextension (age 10 for bus and age 12 for flacon). After the phase of overextension, the naming pattern is gradually narrowed down to an adult-like pattern.

In the bilingual group the same phases emerge. However, the extension of bus is systematically smaller in bilinguals than in their monolingual peers, even in the adult group. Flacon, in contrast, remains overextended in bilingual adults as compared to monolingual adults. Bilinguals thus seem to have a high level of difficulty with these words. It is possible that the difficulty with learning and using bus and flacon is in part due to the fact that there is no close equivalent to these terms in the other language. This possibility is supported by the fact that Tables 3 and 4 of Storms et al. show a much larger gap in the frequency of use of bus and flacon by bilinguals compared to monolinguals than in the frequency of use of several other terms in each language that 
are actually used less by monolinguals.

\section{Discussion}

We had monolingual and bilingual children and adults name pictures of nearly 200 household objects in Dutch and/or French. We replicated the findings by Ameel et al. (2008) and Storms et al. (2015) that both monolingual and bilingual children display an extended lexical learning trajectory. Our results were obtained with a larger stimulus set, providing a more reliable and denser representation of the lexical domain, and using different analyses. As such, they support the generalizability of the previous findings. Critically, we also examined to what extent monolingual children learning different languages and bilinguals learning two languages show shared naming patterns from age 5 onward. We now consider the findings of these analyses.

\section{The monolingual trajectory}

We found that the developmental trajectory of monolingual naming patterns follows the tendency to evolve from a more universal pattern towards a more language-specific pattern. Early word use is to a large degree shared, and differentiation between languages gradually increases. This trajectory of gradual differentiation is consistent with the idea that children first set up conceptual representations independent of language and only later add language-specific representations for talking about experience (e.g., Bowerman \& Choi, 2001, 2003; E. V. Clark, 1995). Most notably, though, the current study shows that this transition takes place only after 5 years old, even for native monolingual speakers of a language.

\section{The bilingual trajectory}

We found that the developmental trajectory of bilingual naming patterns also follows the tendency to evolve from a more universal pattern towards a more language-specific pattern. These findings are consistent with the reanalysis of the data

of Storms and colleagues (2015) by White et al. (2017), showing that bilinguals' naming patterns in their two languages become less similar with age, displaying decreasing 
convergence. Strikingly, the transition for bilinguals is even later than for monolinguals, taking place only in late middle childhood.

Together with the data presented in this paper, these findings provide evidence against the 'increasing convergence hypothesis' (Figure 7, A), which suggested that cross-language influence might increase over time as bilingual children move beyond initial context-bound uses of words and work out broader meanings. The data also shed a new light on the 'decreasing convergence hypothesis' (Figure 7, B) in that we can now conclude that it applies to both monolingual and bilingual children. Both monolingual and bilingual children go through a similar process, although bilingual children do so later and to a lesser extent. Based on the data, we propose the 'gradual differentiation hypothesis' characterizing lexical development patterns of both monolingual and bilingual children presented in Figure 7, Panel C. The lag for bilingual children may be due to less input per language at each age, the need to sort out conflicting input in the two languages, or an initial implicit assumption that the word meanings of their two languages are equivalent (or a combination of these).

As implied by preceding points, patterns of over- and underextension are a part of the transition from shared to language-specific naming patterns for both monolingual and bilingual children. Overextension is present in young age groups and for all labels (see Figure 4, and Appendix C1, and Appendix C1). Patterns of over- and underextension are likely mediated by perceptual similarity between objects (Waxman \& Senghas, 1992). Early naming patterns may resemble each other strongly regardless of the language because the perception of similarity for concrete objects is largely independent of language (Malt et al., 1999). According to this thesis, young children start off with broad and similarity-driven usage patterns and gradually carve out regions of semantic space in a language-specific way.

One might conjecture that the similarities between naming patterns of young children speaking different languages are due to a smaller vocabulary and overextension in young children. However, as suggested in Appendix B the evolution from a shared naming pattern may not be solely attributed to a growing vocabulary. The shift from 
this shared naming pattern to a naming pattern that contains more language-specificities takes place before the growth spurt in the vocabulary.

Similarity driven naming might explain more than the transition from a more universal to a language-specific naming pattern. It is also a plausible explanation for the higher degree of agreement in bilingual naming versus monolingual naming found in Analysis 1 (as well as in Ameel et al., 2005). The higher degree of agreement in bilingual naming cannot be attributed to intra-individual correlations since these are not included in the analyses. Nor can it be explained by differences in vocabulary size, because the differences in bilingual versus monolingual agreement are present even for adults, despite differences in vocabulary size between bilinguals and monolinguals been absent in adulthood (see also Appendix A).

Bilingual children might demonstrate this greater consensus because they have less input in each language compared to monolinguals. The amount of input monolingual children receive of one language is divided over two languages in the case of bilingual children. Bilingual children thus have to construct their vocabulary in a language learning environment that resembles a semi-supervised learning situation, with even less feedback as compared to their monolingual peers (Vandist et al., 2009). Since bilinguals experience more gaps in the input of each language, they might be more inclined to name objects based on perceptual similarity. This is consistent with the findings of Ameel et al. (2009), who found fewer violations to similarity-based naming in bilingual adults.

Monolingual children grow up in an environment in which they receive input in one language, and yet they display naming pattern into middle childhood that are very similar to those of monolingual children growing up with another language. One could have expected children growing up learning different languages to demonstrate different patterns of overextension and therefore different overall naming patterns. The fact that this is not the case is another strong argument for naming based on a shared perception of similarity in young children.

In order to investigate bilingual language development, it is important to have a 
thorough understanding of monolingual language development with all its subtleties. In Storms et al. (2015) the question of how the developmental trajectory looks like for monolingual children was not asked explicitly and it was implicitly assumed that monolinguals start out with a language-specific naming pattern. The insight that monolinguals start out with a shared naming pattern and gradually learn language-specificities is, however, necessary to interpret and characterize the bilingual developmental pattern.

Although our results confirm the claim that bilinguals gradually differentiate between their two languages (White, Malt, Verheyen, \& Storms, 2017), the insight that bilingual development is not fundamentally different from monolingual development is equally important. Arriving at the conclusion that bilinguals follow a universal to language-specific pattern without acknowledging that monolinguals follow a similar pattern could be misleading. Very often bilingualism research focuses on differences between monolingual and bilingual development. Although these differences deepen our insight in the specific challenges of learning two languages in parallel, it is equally insightful to understand shared components of lexical development.

Additional observations. The data also afforded several additional observations about later lexical development. For both monolinguals and bilinguals, the extended period of lexical learning consists of several intertwined aspects. First, as observed in previous studies, with the entry of new words into the lexicon, reorganization has to take place (e.g., Ameel et al., 2008, E. V. Clark, 1995). This development is reflected in early underextension of some terms, followed by overextension and subsequent 'fine tuning' of the naming pattern. This is, however, not the full story. A second aspect of the extended trajectory for later lexical learning is revealed in the current data on inter-individual consensus within age groups, which we found to be quite low at age 5. Children gradually develop a higher level of within-group consensus. Surprisingly, however, the level of agreement between individuals of the same age remained below the adult level even at age 14 . This finding indicates that at age 5 and even well beyond, monolingual and bilingual children's 
hypotheses about what individual words mean and how they can be used are to some extent idiosyncratic in nature.

\section{Conclusion}

This study found that the later lexical development of common nouns displays an evolution from a more universal response pattern to a more language-specific one, both in monolingual and bilingual children. The results are consistent with a gradual differentiation hypothesis suggesting that both monolingual and bilingual children are at first more similarity-driven in their naming patterns and only later start learning the language-specificities of their native tongue. So far, research regarding universality and diversity in language development has been based on comparisons of functionally monolingual learners of different languages. This study is the first to take into account bilingual participants while investigating the development from universality to language-specificity in naming and to show broadly shared developmental evolution as well as an impact of exposure to two languages. As such, it contributes to the understanding of universality versus specificity in language development more broadly, supporting the role of universality in semantics in addition to phonology and morphosyntax. Further, it is demonstrating how language-specificity manifests across development, emerging surprisingly late and even later and to a lesser extent for bilingual than monolingual children. Additionally, this study contributes to previous findings described by Ameel et al. (2008) and Storms et al. (2015) by partially replicating and refining them. 


\section{Acknowledgements}

AW gathered and analyzed the data presented in this paper. All four authors discussed the findings thoroughly, participated in the writing of the manuscript, and approved the final version. We thank Julie Biesmans, Klara Delcourt, Karlien Finck, Emilie Loos, Kim Molders, and Jeremy Van Den Bossche for their help in gathering the children's data, and their schools for permitting access.

\section{Funding}

AW was funded by Fonds Wetenschappelijk Onderzoek (FWO) and by KU Leuven (PDM 18/084). SV was funded by KU Leuven Research Council grant C14/16032 awarded to GS.

\section{Conflict of Interest Statement}

The authors declare that the research was conducted in the absence of any commercial or financial relationships that could be construed as a potential conflict of interest. 


\section{References}

Ameel, E., Malt, B. C., \& Storms, G. (2008). Object naming and later lexical development: From baby bottle to beer bottle. Journal of Memory and Language, 58, 262-285. doi:10.1016/j.jml.2007.01.006

Ameel, E., Malt, B. C., \& Storms, G. (2014). Steps along a continuum of word knowledge: Later lexical development through the lens of receptive judgments. Language Learning and Development, 10, 234-262. doi:10.1080/15475441.2013.840485

Ameel, E., Malt, B. C., Storms, G., \& Van Assche, F. (2009). Semantic convergence in the bilingual lexicon. Journal of Memory and Language, 60, 270-290. doi:10.1016/j.jml.2008.10.001

Ameel, E., Storms, G., Malt, B. C., \& Sloman, S. A. (2005). How bilinguals solve the naming problem. Journal of Memory and Language, 53, 60-80. doi:10.1016/j.jml.2005.02.004

Borg, I. \& Groenen, P. (2005). Modern multidimensional scaling: Theory and applications. New York: Springer.

Bowerman, M. \& Choi, S. (2001). Shaping meanings for language: Universal and language-specific in the acquisition of semantic categories. In Language acquisition and conceptual development (pp. 475-511). Cambridge University Press.

Bowerman, M. \& Choi, S. (2003). Space under construction: Language-specific spatial categorization in first language acquisition. In Language in mind: Advances in the study of language and cognition (pp. 387-428).

Brown, P. (1998). Children's first verbs in tzeltal: Evidence for an early verb category. Linguistics, 36. doi:10.1515/ling.1998.36.4.713

Brown, R. (1973). A first language: The early stages. Harvard U. Press.

Carey, S. (1978). The child as word learner. In M. Halle, J. Bresnan, \& G. A. Miller (Eds.), Linguistic theory and psychological reality (pp. 264-293). Cambridge, MA: MIT Press. 
Clark, E. V. (1973). What's in a word? on the child's acquisition of semantics in his first language. In T. Moore (Ed.), Cognitive development and the acquisition of lanuguage (pp. 65-110). New York: Academic Press.

Clark, E. V. (1995). The lexicon in acquisition. Cambridge University Press.

Clark, E. V. (2001). Emergent categories in first language acquisition. In M. Bowerman \& S. Levinson (Eds.), Language acquisition and conceptual development (pp. 379-405). Cambridge University Press. doi:10.1017/cbo9780511620669.015

Clark, H. H. (1973). The language-as-fixed-effect fallacy: A critique of language statistics in psychological research. Journal of verbal learning and verbal behavior, 12, 335-359. doi:10.1016/s0022-5371(73)80014-3

Golinkoff, R. M. \& Hirsh-Pasek, K. (2008). How toddlers begin to learn verbs. Trends in Cognitive Sciences, 12, 397-403. doi:10.1016/j.tics.2008.07.003

Hespos, S. J. \& Spelke, E. S. (2004). Conceptual precursors to language. Nature, 430, 453-456. doi:10.1038/nature02634

Hohenstein, J. M. (2005). Language-related motion event similarities in english-and spanish-speaking children. Journal of Cognition and Development, 6, 403-425. doi:10.1207/s15327647jcd0603_5

Kruskal, J. B. \& Wish, M. (1991). Multidimensional scaling. Newbury Park: Sage. Kuhl, P. K. (2000). A new view of language acquisition. Proceedings of the National Academy of Sciences, 97, 11850-11857. doi:10.1073/pnas.97.22.11850

Maguire, M. J., Hirsh-Pasek, K., Golinkoff, R. M., Imai, M., Haryu, E., Vanegas, S., .. . Sanchez-Davis, B. (2010). A developmental shift from similar to language-specific strategies in verb acquisition: A comparison of english, spanish, and japanese. Cognition, 114, 299-319. doi:10.1016/j.cognition.2009.10.002

Malt, B. C. \& Majid, A. (2013). How thought is mapped into words. Wiley Interdisciplinary Reviews: Cognitive Science, 4, 583-597. doi:10.1002/wcs.1251

Malt, B. C., Sloman, S. A., Gennari, S., Shi, M., \& Wang, Y. (1999). Knowing versus naming: Similarity and the linguistic categorization of artifacts. Journal of Memory and Language, 40, 230-262. doi:10.1006/jmla.1998.2593 
Markman, E. M. (1990). Constraints children place on word meanings. Cognitive Science, $14(1), 57-77$.

Pallier, C., Christophe, A., \& Mehler, J. (1997). Language-specific listening. Trends in Cognitive Sciences, 1, 129-132. doi:10.1016/s1364-6613(97)01044-9

Rosenberg, S. \& Kim, M. P. (1975). The method of sorting as a data-gathering procedure in multivariate research. Multivariate Behavioral Research, 10, 489-502. doi:10.1207/s15327906mbr1004_7

Saji, N., Imai, M., Saalbach, H., Zhang, Y., Shu, H., \& Okada, H. (2011). Word learning does not end at fast-mapping: Evolution of verb meanings through reorganization of an entire semantic domain. Cognition, 118, 45-61. doi:10.1016/j.cognition.2010.09.007

Slobin, D. I. (1985). Crosslinguistic evidence for the language-making capacity. In D. I. Slobin (Ed.), The crosslinguistic study of language acquisition (pp. 1157-1256). Hillsdale, NJ: Lawrence Erlbaum Associates.

Storms, G., Ameel, E., \& Malt, B. C. (2015). Development of cross-language lexical influence. International Journal of Bilingual Education and Bilingualism, 18, 529-547. doi:10.1080/13670050.2015.1027142

Tillman, K. A. \& Barner, D. (2015). Learning the language of time: Children's acquisition of duration words. Cognitive Psychology, 78, 57-77. doi:10.1016/j.cogpsych.2015.03.001

Vandist, K., Schryver, M. D., \& Rosseel, Y. (2009). Semisupervised category learning: The impact of feedback in learning the information-integration task. Attention, Perception, ES Psychophysics, 71, 328-341. doi:10.3758/app.71.2.328

Verheyen, S., Ameel, E., \& Storms, G. (2011). Overextensions that extend into adolescence: Insights from a threshold model of categorization. In L. Carlson, C. Hölscher, \& T. F. Shipley (Eds.), Proceedings of the 33rd annual conference of the cognitive science society (pp. 2000-2005). Austin, TX: Cognitive Science Society. 
Waxman, S. R. \& Senghas, A. (1992). Relations among word meanings in early lexical development. Developmental Psychology, 28, 862-873.

doi: $10.1037 / 0012-1649.28 .5 .862$

White, A., Malt, B. C., \& Storms, G. (2017). Convergence in the bilingual lexicon: A pre-registered replication of previous studies. Frontiers in Psychology, 7. doi:10.3389/fpsyg.2016.02081

White, A., Malt, B. C., Verheyen, S., \& Storms, G. (2017). Commentary: Development of cross-language lexical influence. International Journal of Bilingual Education and Bilingualism.

Zinszer, B. D., Malt, B. C., Ameel, E., \& Li, P. (2014). Native-likeness in second language lexical categorization reflects individual language history and linguistic community norms. Frontiers in Psychology, 5. doi:10.3389/fpsyg.2014.01203 
Table 1

Number of participants per age, language and speaker group.

\begin{tabular}{llll}
\hline age group & monolingual Dutch & monolingual French & bilingual Dutch - French \\
\hline 5 & 29 & 30 & 30 \\
8 & 30 & 30 & 25 \\
10 & 30 & 30 & 16 \\
12 & 30 & 26 & 22 \\
14 & 30 & 27 & 27 \\
adults & 32 & 30 & 30 \\
\hline
\end{tabular}


Table 2

Average self-or parent-reported proficiency and standard deviation for Dutch and French for bilinguals on a 7-point scale.

\begin{tabular}{lll}
\hline age & Dutch & French \\
\hline 5 & $6.23(0.90)$ & $4.83(1.49)$ \\
8 & $6.48(0.77)$ & $4.88(1.24)$ \\
10 & $5.88(1.02)$ & $5.31(1.25)$ \\
12 & $6.32(0.84)$ & $5.05(0.90)$ \\
14 & $6.11(0.93)$ & $5.52(1.09)$ \\
adults & $6.35(0.84)$ & $5.52(0.84)$ \\
\hline
\end{tabular}



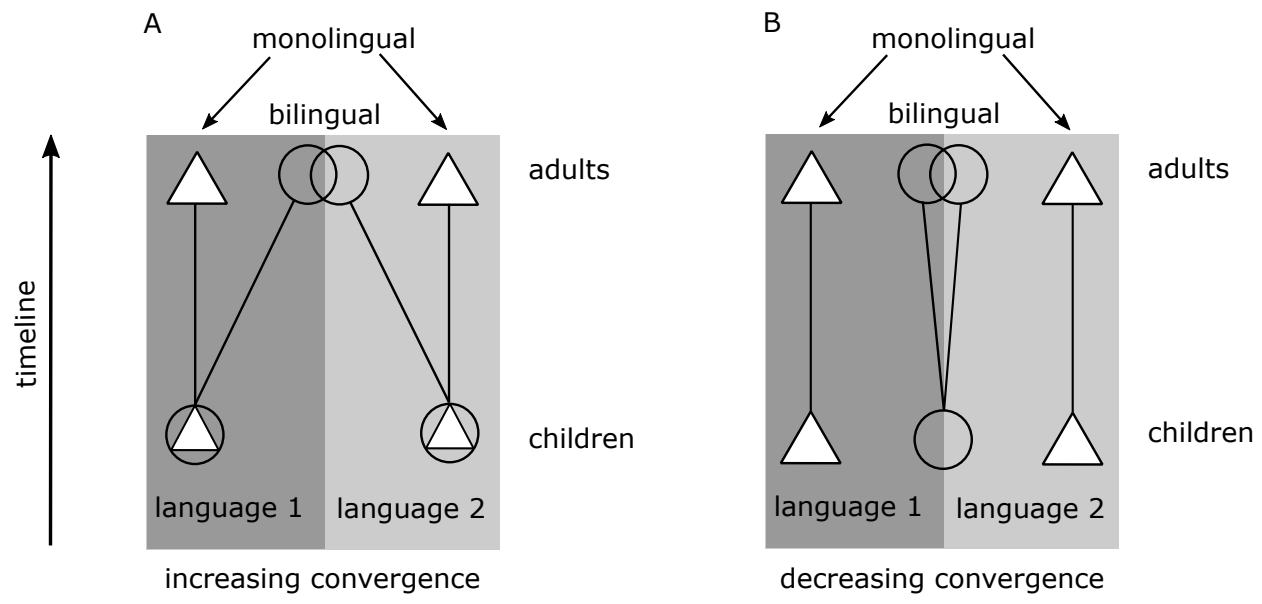

Figure 1. Possible trajectories of convergence in bilingual lexical development: (A) increasing convergence, and (B) decreasing convergence (from Storms, Ameel, \& Malt, 2015 ). 

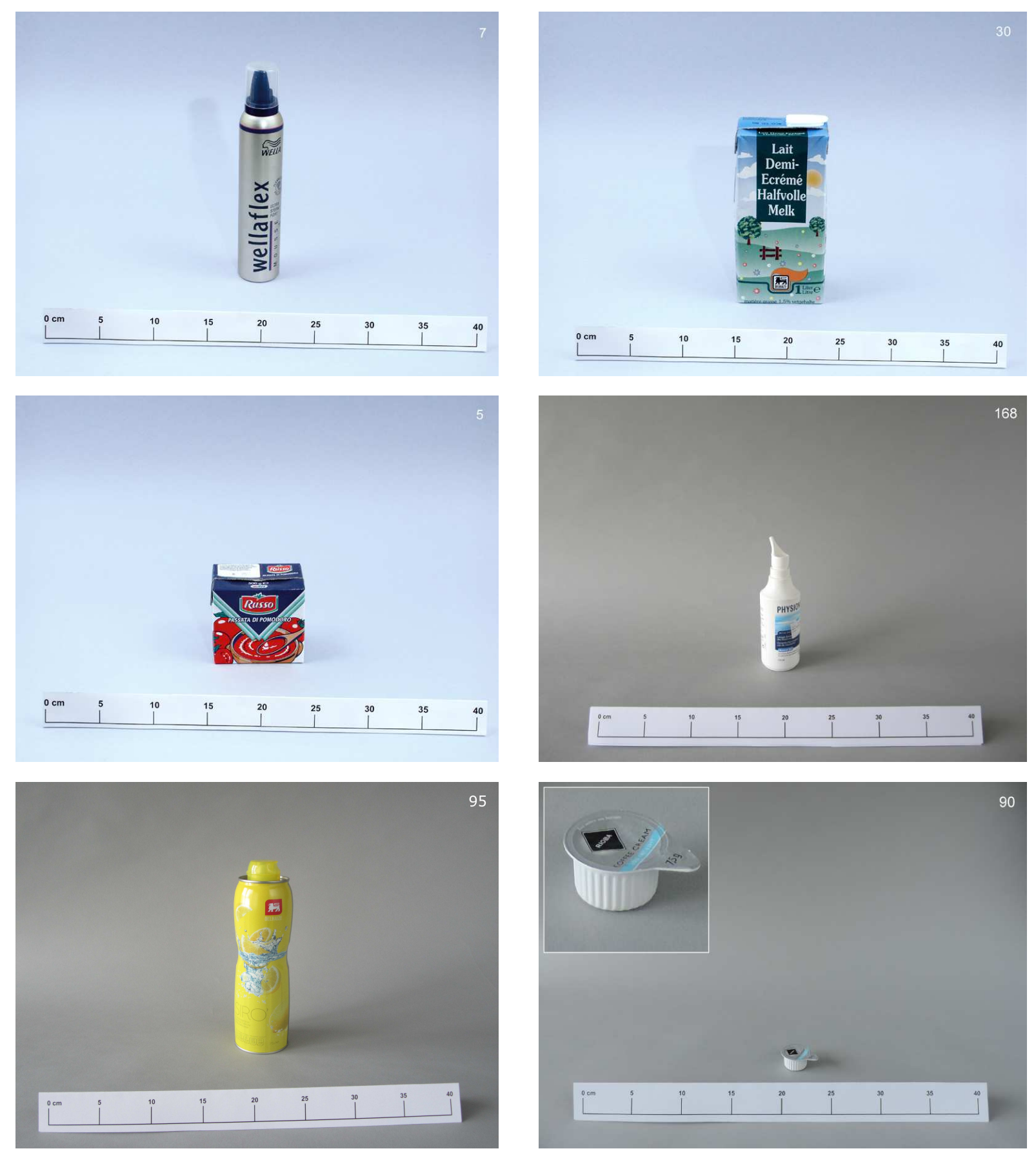

Figure 2. Sample stimulus pictures. 

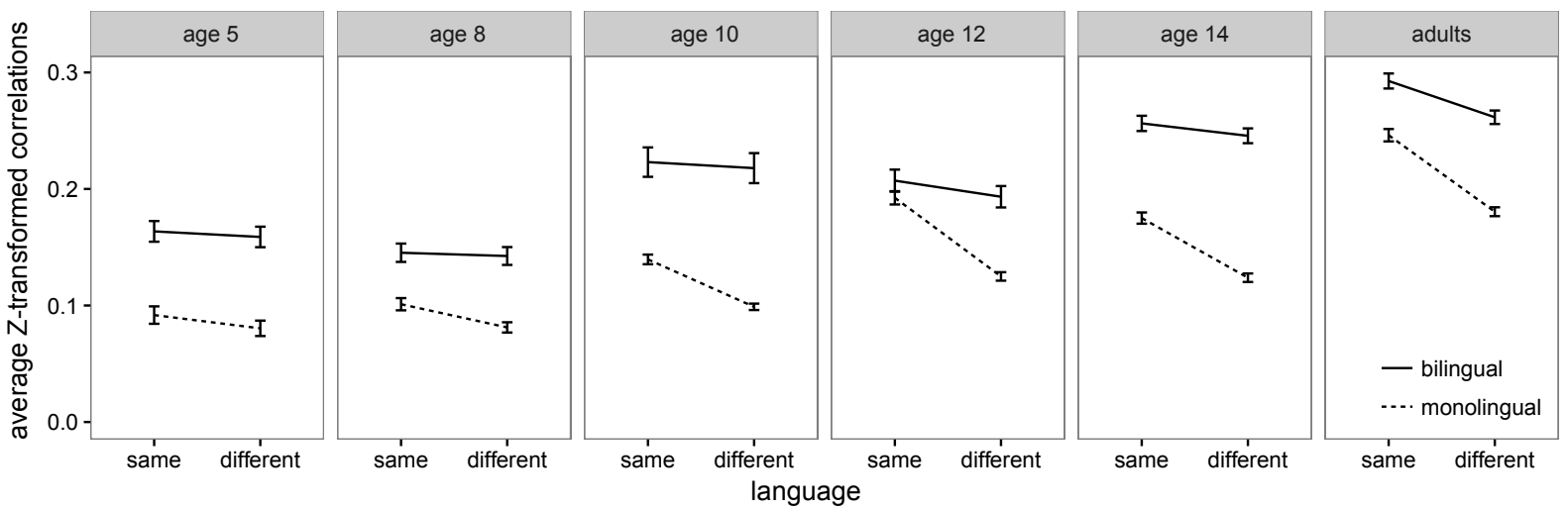

Figure 3. The language effect for every age and speaker group. The points in the graph represent the average Z-transformed correlations (with $95 \%$ confidence intervals) between two different individuals within an age group in the same versus in a different language for bilinguals (solid line) and monolinguals (dotted line). 


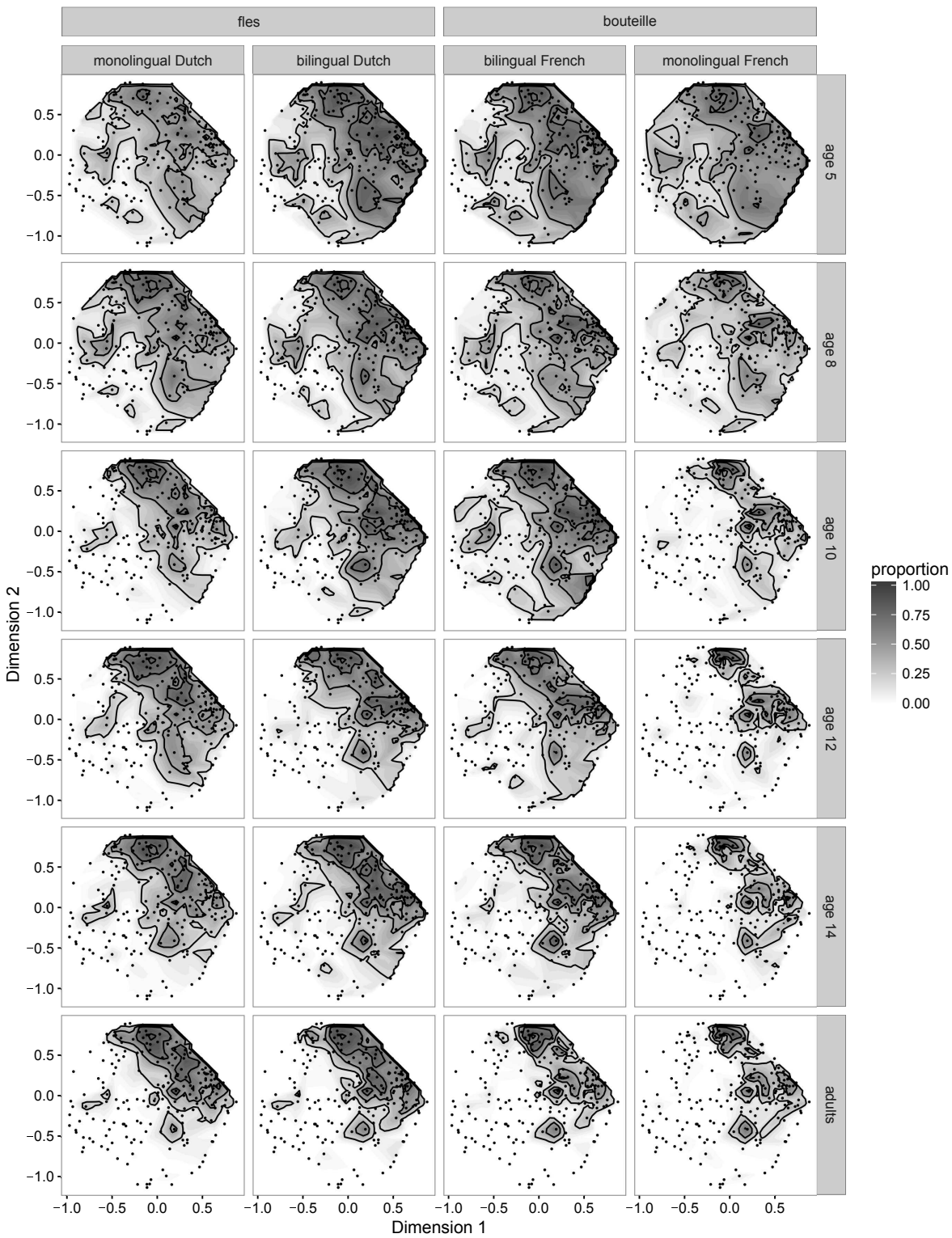

Figure 4. Naming pattern of fles and bouteille for monolinguals and bilinguals. 


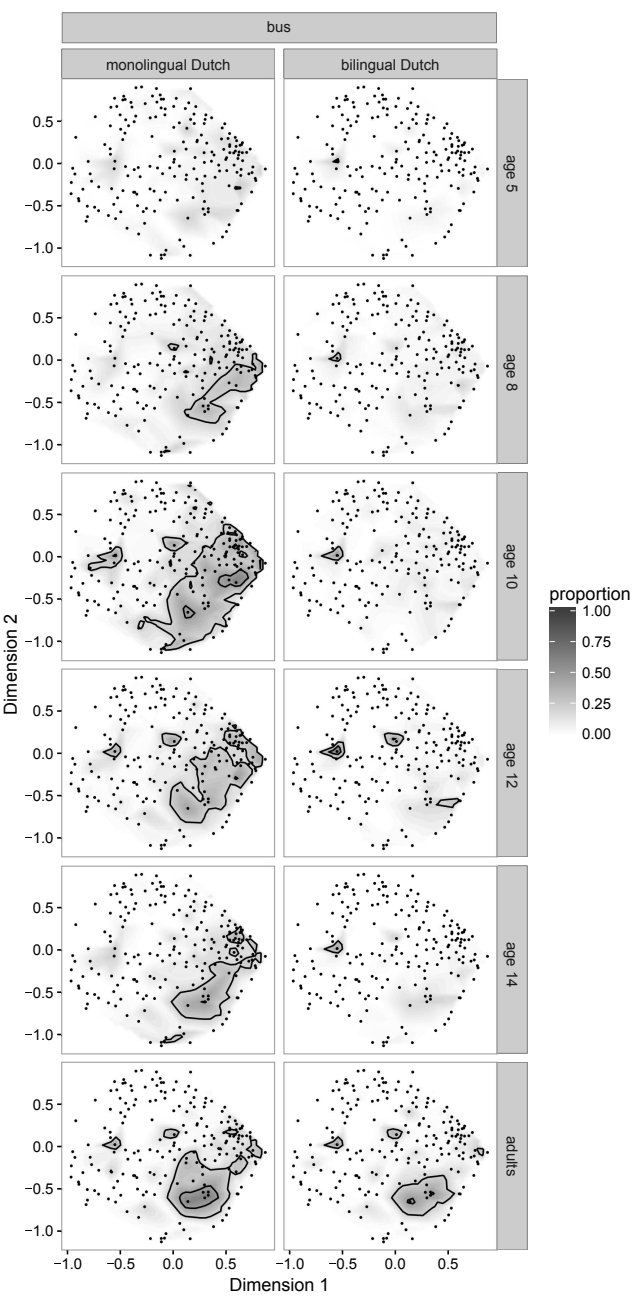

Figure 5. Naming pattern of bus for monolinguals and bilinguals.

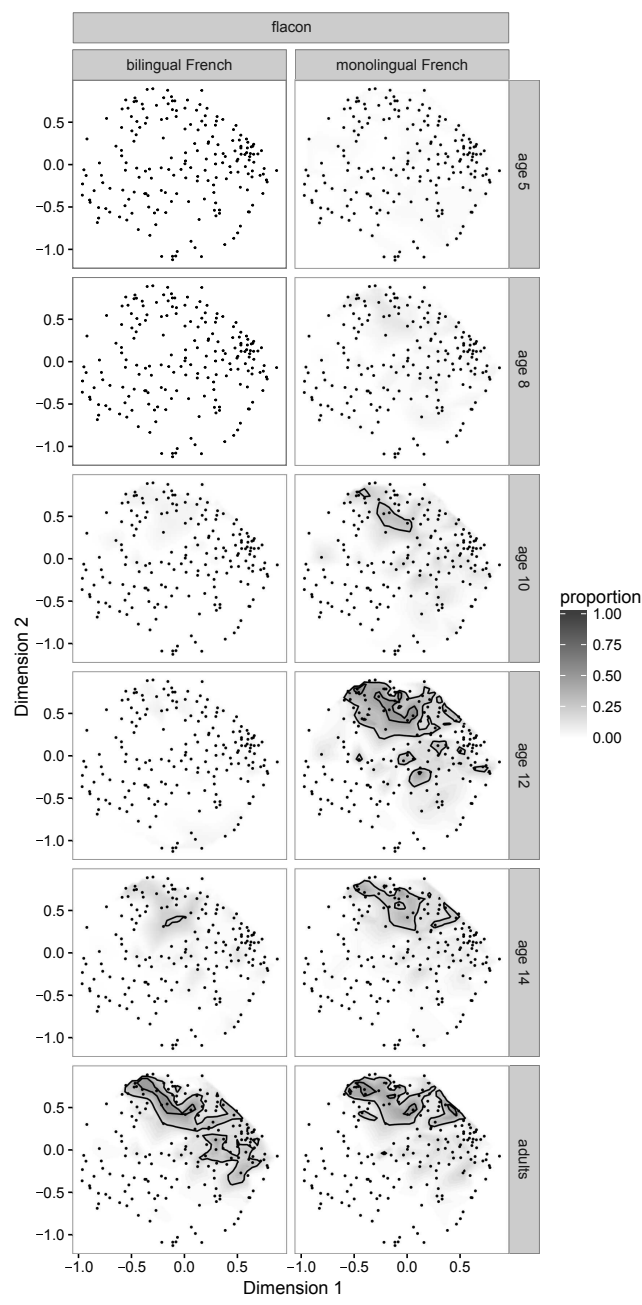

Figure 6. Naming pattern of flacon for monolinguals and bilinguals. 

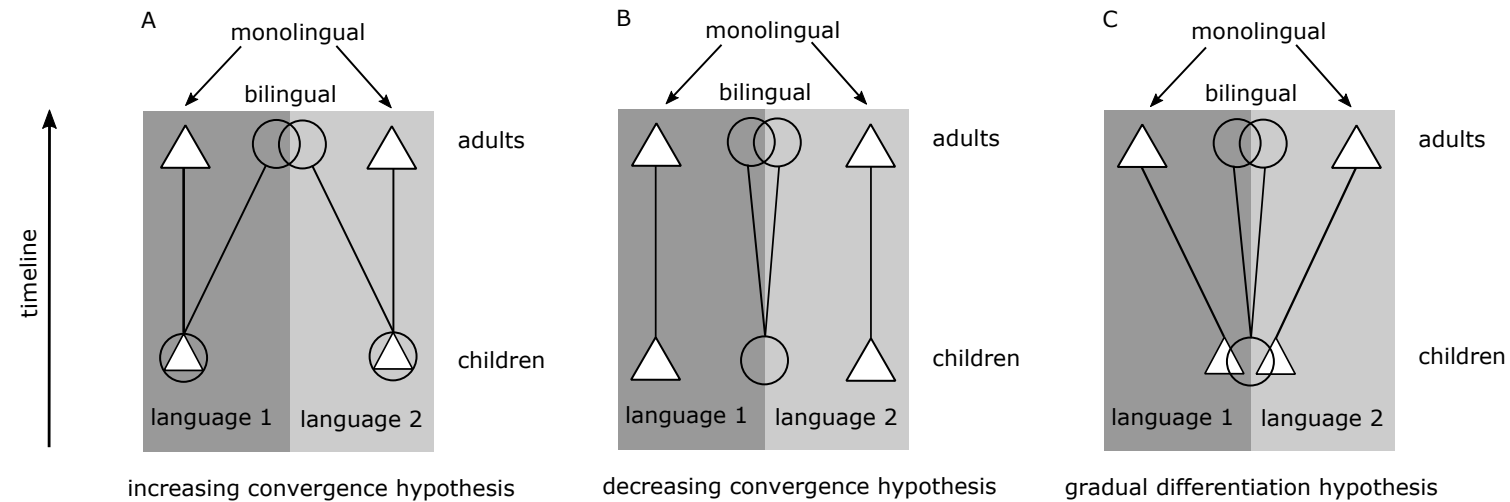

Figure 7. Bilingual lexical development according to (A) the increasing convergence hypothesis, (B) the decreasing convergence hypothesis, and the $(\mathrm{C})$ the gradual differentiation hypothesis. 
Appendix A

Vocabulary size

The average number of different names produced by individuals of a specific age, language and speaker group across all stimuli is an indication of vocabulary size. Table A1 displays the average number of different names produced for each language and speaker group per age. For both languages a 2 (speaker group: bilinguals versus monolinguals) by 6 (age groups) factorial design analysis of variance was performed. In both French and Dutch there was a significant main effect of age (with $F(5,314)=$ $148.39, p<.001$ for French, and $F(5,319)=107.05, p<.001$ for Dutch). The age effect reflects an increasing vocabulary size with increasing age for both languages. For French a main effect of speaker group revealed that, on average, the monolingual values differ from the bilingual values $(F(1,314)=136.77, p<.001)$. As Table A1 shows, the speaker group effect reflects a tendency toward a smaller vocabulary size in bilinguals for French. The effect of speaker group was absent in Dutch $(F(1,319)=1.73, p=$ .20). For French, the interaction between age and speaker group was also significant, $F(5,314)=10.32, p<.001$. The vocabulary size of the bilinguals in French is significantly smaller than that of the monolinguals for all ages, except in adults. For Dutch, there is no difference in vocabulary size between monolinguals and bilinguals. It thus seems that the participants in this study are dominant in Dutch (see also the language background information) and build up a rich vocabulary in their dominant language from an early age onward, and they catch up with monolinguals in adulthood for their non-dominant language.

Table A1 Average number of different names produced by individuals across all stimuli.

\begin{tabular}{lllllll}
\hline & 5-year olds & 8-year olds & 10-year olds & 12-year olds & 14-year olds & adults \\
\hline Dutch & & & & & & \\
Monolinguals & 10.9 & 11.2 & 13.6 & 15.6 & 16.3 & 25.1 \\
Bilinguals & 8 & 9.2 & 15.9 & 15.1 & 16.2 & 25.2 \\
$\begin{array}{l}\text { French } \\
\text { Monolinguals }\end{array}$ & 10.5 & 11.8 & 16.3 & 24.1 & 25.3 & 27.7 \\
Bilinguals & 6.1 & 7.2 & 9.1 & 13.2 & 15.4 & 27.4 \\
\hline
\end{tabular}




\section{Appendix B}

Lexical differentiation and vocabulary size

The development from a more universal to a language-specific naming pattern cannot be explained by the smaller vocabulary size in the youngest age groups. In Analysis 1 we demonstrate a slow and gradual increase of lexical differentiation with increasing age. To investigate how this increasing differentiation is related to the growing vocabulary, we identified a tipping point when the naming pattern of children switches from more universal than language-specific to more language-specific than universal. We then compared the timing of this tipping point with the pattern of vocabulary growth. If the timing of the tipping point corresponds to the timing of sudden jumps in vocabulary growth, we can assume that both are related. If this is not the case, there is no direct relation between lexical differentiation and vocabulary size. The analysis was done only for monolingual participants, since bilinguals only show a small extent of language-specificity even in the adult group.

In order to identify the tipping point, we first constructed name distribution matrices for monolingual children and adults in Dutch and French. A name distribution matrix is an object $\mathrm{x}$ name matrix, that indicates the number of times every name was produced for every object. Second, a name similarity matrix (object x object matrix) was constructed by correlating the name distribution of an object with the name distribution of every other object using a Pearson correlation for all (192 x [192 - 1]) / 2 possible object pairs. The correlations in the similarity matrices reflect the extent to which 2 objects share a similar naming pattern within one language group.

When children use a more universal naming pattern, we expect the correlation between two groups of children from the same age, speaking a different language to be larger than the correlation between children and adults speaking the same language. When children use a language-specific pattern the correlation between children of the same age, speaking a different language will be smaller than the correlation between children and adults speaking the same language. The tipping point between universal and language-specific is the switch from the first to the latter situation. The 
correlations between children of the same age, speaking a different language and children and adults speaking the same language were calculated using the similarity matrices of every group and were corrected for unreliability using the Spearman-Brown formula. An overview of these correlations can be found in Table B1.

We can observe a clear decreasing trend in the correlation between children of the same age, speaking a different language. The correlation between children and adults speaking the same language shows a clearly increasing trend with age, both in Dutch and in French. Important for our analysis is the tipping point from universal to language-specific. This tipping point is reached between age 8 and 10. For 8 year olds the correlation between children speaking a different language is larger than between 8 year olds and adults speaking the same language. This is not the case anymore at age 10.

Table B1

Similarity based correlations between monolingual children of the same age, children and adults in Dutch and French corrected for unreliability with the Spearman-Brown formula.

\begin{tabular}{llll}
\hline age & same age, Dutch - French & children - adults, Dutch & children - adults, French \\
\hline 5 & 0.88 & 0.69 & 0.50 \\
8 & 0.79 & 0.72 & 0.67 \\
10 & 0.70 & 0.83 & 0.85 \\
12 & 0.67 & 0.88 & 0.92 \\
14 & 0.67 & 0.92 & 0.92 \\
\hline
\end{tabular}

In Graph B1 we see that there are two vocabulary growth spurts. For Dutch vocabulary this growth spurt takes place between age 14 and adult age, for French between age 10 and 12 . Since the vocabulary shows a major growth only after the switch from a universal to a language-specific naming pattern, we conclude that lexical differentiation is not just due to vocabulary growth spurts. 


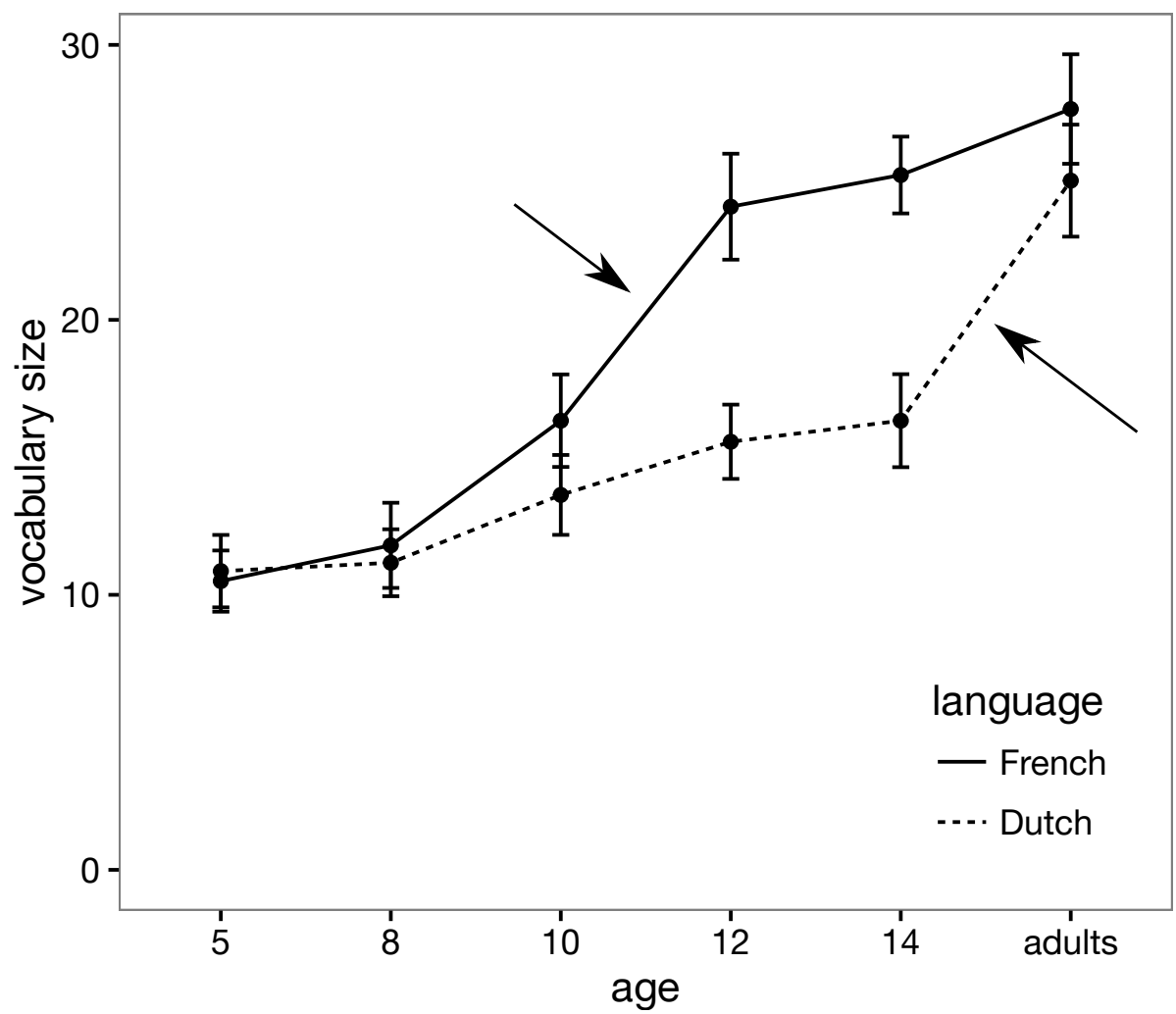

Figure B1. Increase of vocabulary size with age. Vocabulary size was measured as the average number of different names produced across individuals. 
Appendix C

Naming patterns

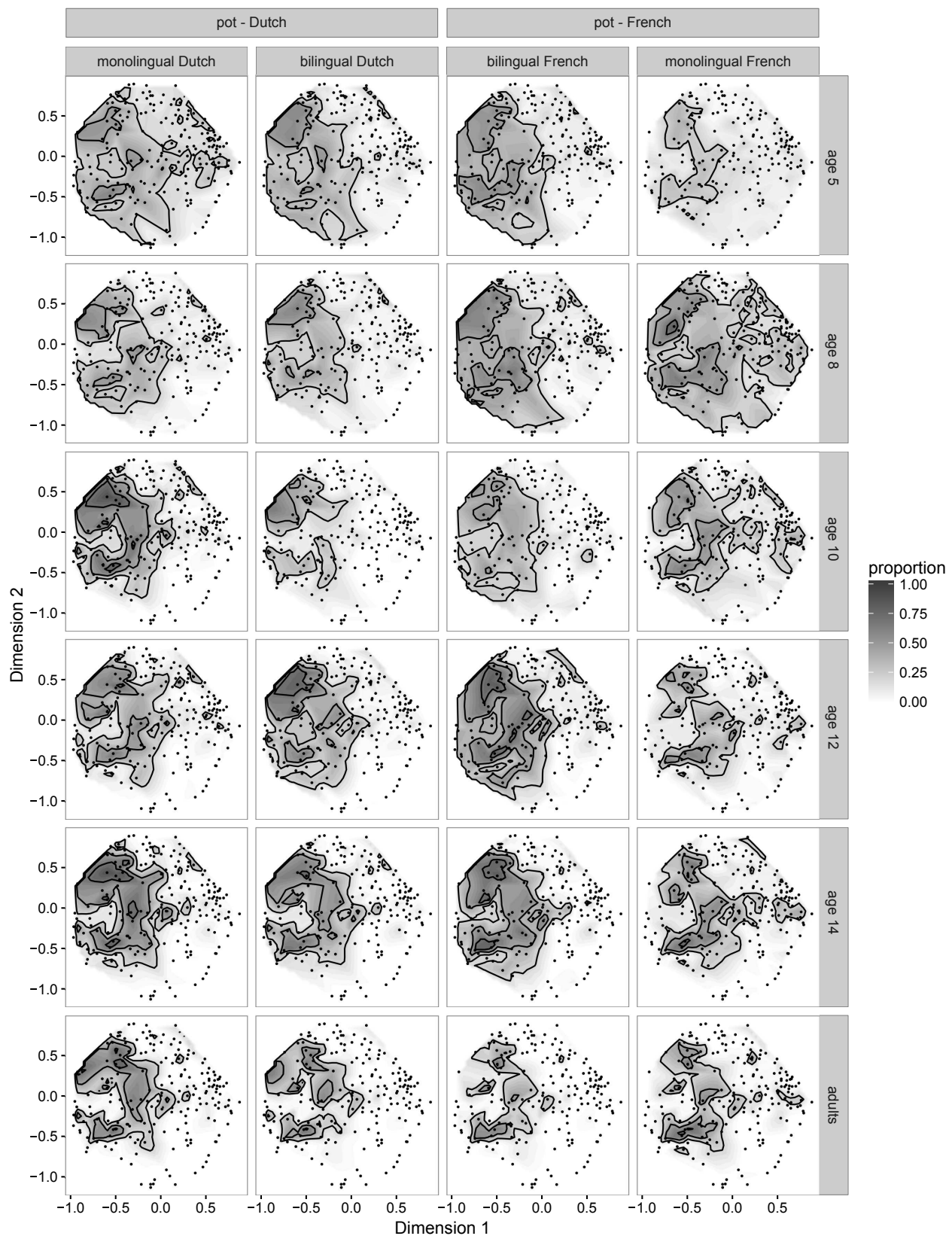

Figure $C 1$. Naming pattern of pot $_{\text {Dutch }}$ and pot $_{\text {French }}$ for monolinguals and bilinguals. 


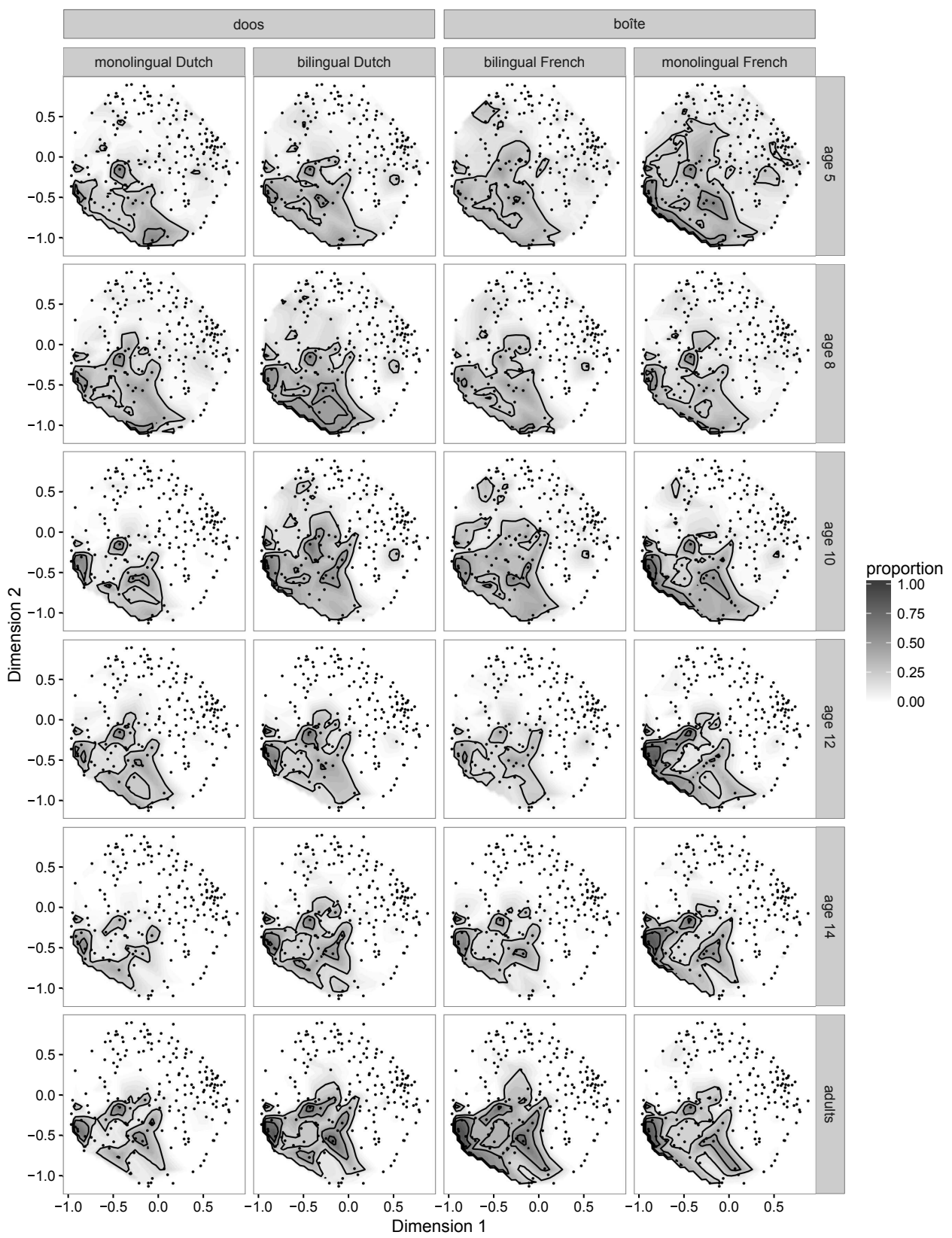

Figure C2. Naming pattern of doos and boite for monolinguals and bilinguals. 